\title{
Investigation of Indoor Air Quality at Shooting Range
}

\author{
S. Yeser Aslanoglu ${ }^{1}$, Fatma Ozturk ${ }^{2}$, Gulen Gullu ${ }^{1}$ \\ ${ }^{1}$ Hacettepe University, Department of Environmental Engineering \\ Beytepe Campus, Ankara, Turkey \\ yaslanoglu@ hacettepe.edu.tr; ggullu@hacettepe.edu.tr \\ ${ }^{2}$ Abant Izzet Baysal University, Department of Environmental Engineering \\ Golkoy Campus, Bolu, Turkey \\ oztfatma@gmail.com
}

\section{Extended Abstract}

Explosion feature of gunpowder has been used in many fields since being invented by the Chinese in mid 800s. The gunpowder has initially used to create huge explosions and also it has been used in developing firearms since the $13^{\text {th }}$ century. The emergence of light firearms, today known as rifles and pistols, are dated in the $17^{\text {th }}$ century. Except for the usage of destruction purposes, the most innocent application field of guns is sports. Furthermore, shooting is among the nine sports branches, which have formed the first modern Olympic Games has held in Athens in 1896. Becoming a skilled shooter needs long training time, intensive labour, accuracy, precision, high stability, and focus. Today, actual pellets, bullets, and cartridges are used in Olympic shooting sub branches, which are air-guns, fire-guns, and shot-guns, respectively. In addition, biathlon and modern pentathlon athletes have to use this type of ammunition, which is mostly consist of lead.

A professional shooting athlete shots millions of pellets, bullets or cartridges throughout her/his sports life from the age about 13. This can cause a high rate of metal and its by product exposure, specifically lead. On the other hand, shooting ranges vary for the type of shooting event as outdoor and indoor. It has been known that outdoor shooting ranges may reduce personal exposure, but this time they are emerging soil and water contamination problems.

The objective of this study is to determine both metals and total carbon (TC) of a world cup standard shooting range's ambient air during $50 \mathrm{~m}$ competitions, which are officially held by Turkish Shooting and Hunting Federation. To this end, particulate matter samples with aerodynamic diameter less than $10 \mu \mathrm{m}\left(\mathrm{PM}_{10}\right)$ were collected by TECORA Skypost PM Sampler on quartz fiber filters. Collected filter samples were conditioned at constant temperature $\left(20-25^{\circ} \mathrm{C}\right)$ and humidity (25-30\%) before and after sampling to calculate PM mass. In order to prevent the carbon loss, filter samples were stored at $-18^{\circ} \mathrm{C}$ both before and after the sampling process till to the analysis. A punch of collected samples $\left(1.5 \mathrm{~cm}^{2}\right)$ were analysed in terms of elemental carbon (EC), organic carbon (OC) and TC (EC+OC) by Sunset Lab (USA) thermal-optical aerosol analyser by following the National Institute for Occupational Health and Safety (NIOSH) 870 protocol. Average PM, OC, $\mathrm{EC}$, and TC concentrations were found as $28.71 \pm 8.88,4.74 \pm 0.55,0.25 \pm 0.09,4.99 \pm 1.59 \mu \mathrm{g} / \mathrm{m}^{3}$, respectively. One-day $\mathrm{PM}_{10}$ sample was analysed by Wavelength Dispersive X-ray Fluorescence Spectrometer (WDXRF) in terms of metals including lead. Crustal enrichment factor was calculated for the metals by taking $\mathrm{Al}$ as reference element, which revealed that $\mathrm{S}, \mathrm{Zn}$ and $\mathrm{Pb}$ were highly enriched in the shooting range's ambient air implying not only $\mathrm{Pb}$ but also $\mathrm{Zn}$ and $\mathrm{S}$ were the metals released to indoor at elevated concentrations during shooting. Even though the same type of bullet was used for the rifle and pistol shots, the released PM and carbon concentrations from pistol shots were found to be 1.5 times higher than that from rifle shots. 